\title{
Éramos felizes e sabíamos ${ }^{1}$
}

\author{
Fátima Regina Évora \\ Unicamp
}

\section{RESUMO}

Neste texto pretendo dizer alguma coisa sobre a criação, referida por Porchat como uma epopeia, e consolidação do CLE e do Programa de pós-graduação em Filosofia da UNICAMP. O Prof. Porchat chegou à UNICAMP, em I975, e trouxe consigo um pequeno projeto, que submeteu ao entáo reitor da Unicamp, Prof. Zeferino Vaz. A proposta contemplava a implantaçáo de um Centro de estudos e pesquisas nas áreas de Lógica, Epistemologia e História da Ciência bem como a criação de um programa de pós-graduação em Lógica e Filosofia da Ciência. Tal projeto, além de preencher uma grande lacuna, converteria a Unicamp, na década de setenta, num local privilegiado de encontro e diálogo entre filósofos, lógicos, historiadores, sociólogos, matemáticos, físicos, psicanalistas até então dispersos nos vários centros universitários do país. O Prof. Zeferino entusiasmou-se com a ideia já na primeira reunião (ocorrida ao final de 1975 ) e meses depois uma dezena de filósofos já havia sido contratada para a implantaçáo do CLE e também do Curso de Pós-Graduação em Lógica e Filosofia da Ciência junto ao Departamento de Filosofia. A marca que o Prof. Porchat imprimiu neste programa, neste período, e que o caracterizava era a atmosfera de debate e de discussão que se instalou ali.

\section{PALAVRAS-CHAVE}

História da Filosofia no Brasil;

Oswaldo Porchat.

\section{ABSTRACT}

In this text I intend to say something about the creation, referred to by Porchat as an epic, and consolidation of the CLE and the postgraduate program in Philosophy at UNICAMP. Prof. Porchat arrived at UNICAMP, in 1975, and brought with him a small project, which he submitted to the then president of Unicamp, Prof. Zeferino Vaz. The proposal included the establishment of a Center for studies and research in the areas of Logic, Epistemology and History of Science as well as the creation of a postgraduate program in Logic and Philosophy of Science.

\section{KEY WORDS}

Brazilian History of Philosophy;

Oswaldo Porchat.

\footnotetext{
Este título é menção a uma conferência intitulada "Eu era feliz e não sabia" proferida pelo Professor Porchat no V Encontro Nacional de Filosofia da ANPOF ocorrido em Diamantina de I9 a 23 de outubro de 1992. Naquela ocasião, claramente, Porchat fazia uma referência ao último verso do clássico de Ataúfo Alves: Meus tempos de criança.
} 
O objetivo deste texto é fazer um relato, a partir de uma perspectiva muito particular, sobre a criação e consolidação do Centro de Lógica, Epistemologia e História da Ciência-CLE e do Programa de pós-graduaçáo em Filosofia da UNICAMP. Estas duas criaçôes, obras do Prof. Oswaldo Porchat, aconteceram conjuntamente e eram referidas por ele como partes de uma epopeia ${ }^{2}$. Neste texto recupero a saudaçáo que fiz, em $20 I^{3}$, por ocasião da outorga do título de Professor Emérito ao Prof. Porchat, ou simplesmente, Porchat, como ele gostava de ser chamado. Aliás, ter sido convidada pelo Porchat para ser sua madrinha e consequentemente para fazer a saudação naquela cerimônia de outorga do título de Professor Emérito a ele foi, sem sombra de dúvida, a maior honra que recebi em toda a minha vida acadêmico-institucional.

Mestre de toda uma geração de filósofos brasileiros, Porchat foi, sem dúvida, um filósofo extraordinário e uma figura ímpar. Todos que conviveram com ele têm um "caso" para contar. Eu não seria diferente. Além de ser um pensador dos mais finos e argutos deste país, com uma capacidade de síntese invejável, Porchat destacou-se também por sua disposição generosa de trabalhar institucionalmente, não apenas na criação de Departamentos e Centros de Pesquisas, mas especialmente na consolidação do sistema brasileiro de pós-graduação em filosofia, e consequentemente da pesquisa em filosofia no Brasil, que muito deve a ele. Digo isso por que falar em pesquisa em filosofia no Brasil é, a meu ver, falar do sistema de pós-graduaçáo em filosofia. Obviamente, não estou afirmando que antes da implementação do sistema brasileiro de pós-graduação em filosofia não havia pesquisa nesta área no Brasil. Mas, a meu ver, não há dúvida que a institucionalização da pesquisa em filosofia passa pela implementação e consolidação da sua pós-graduação.

Antes da consolidação do sistema brasileiro de pós-graduação em filosofia havia, certamente, alguns importantes cursos de pós-graduação em filosofia, como o da USP, e pesquisas isoladas e grupos isolados com trabalhos bastante sólidos, mas que não interagiam entre si. Havia também alguns poucos grupos nacionais de filosofia, tais como o Instituto Brasileiro de Filosofia (IBF), a Sociedade de Filósofos Católicos e finalmente a SEAF (Sociedade de Estudos e Atividades Filosóficas) ${ }^{4}$, fundada

\footnotetext{
2 Artigo escrito a partir de minha conferencia "Porchat e a criação do Centro de Lógica, Epistemologia e História da Ciência-CLE e do Programa de pós-graduação em Filosofia da UNICAMP: eu era feliz e não sabia", proferida no Colóquio "Ceticismo, Filosofia e História da Filosofia: Homenagem a Oswaldo Porchat", realizado no Departamento de Filosofia, FFLCH-USP, de I3 a I6 de agosto de 20I8. Eu gostaria de agradecer ao convite que o Prof Roberto Bolzani me fez para participar deste evento, em homenagem do Professor Porchat, e para dividir a mesa de abertura com o Prof. José Arthur Giannotti.

3 Ver: "Unicamp concede o título de professor emérito ao filósofo Oswaldo Porchat", 23/II/20II, http://www.unicamp.br/unicamp/noticias/20I//unicamp-concede-o-t\% $\mathrm{C}_{3} \%$ ADtulo-de-professorem\% 3 \% A 9rito-ao-fil\% 3 \%B 3 sofo-oswaldo-porchat

4 Conforme entrevista de Landin publicada em Nobre, 2000, p. 259.
} 
pelo Prof. Olinto Pegoraro, e que reunia um grupo de pessoas trabalhando filosofia no Brasil e não apenas localmente. A SEAF, como apontou Raul Landin em uma entrevista por ele dada a Marcos Nobre, e publicada em 2000, no livro Conversas com Filósofos Brasileiros, "foi durante o período da ditadura militar um espaço de liberdade para discussão e debate filosófico" (Landin, apud Nobre, 2000, p. 259). Portanto, não podemos ignorar a importância filosófica e política da SEAF, que não estava associada ao sistema de pós-graduação. Contudo, a importância da SEAF foi diminuindo ao longo da década de setenta, quando começaram a surgir outras formas de organização e outros canais de debates filosóficos.

É neste contexto que foi criado, pelo Prof. Oswaldo Porchat, o Centro de Lógica, Epistemologia e História da Ciência-CLE e o Programa de Pós-graduação em Filosofia da UNICAMP. Ambos desempenharão, a meu ver, um papel fundamental no desenvolvimento da pesquisa filosófica neste país, criando novos espaços de debates e discussóes, reunindo pesquisadores de diversas partes do país e do mundo. Apenas a título de ilustração, quando eu entrei na pós-graduação na UNICAMP, no início da década de oitenta, havia apenas doze cursos de mestrado em Filosofia e três de doutorado (USP, UNICAMP e UFRJ). No correr dos últimos trinta e oito anos o número de cursos de mestrado em Filosofia quase que quadruplicou e o crescimento dos cursos de doutorado foi ainda maior 5 .

Porchat chegou à UNICAMP, no dia Io de setembro de 1975, estimulado, segundo ele relata, pelo seu querido amigo e então professor do Instituto de Física da UNICAMP, e, na ocasiáo, Coordenador das Faculdades: Rogério Cezar de Cerqueira Leite. E na Unicamp Porchat permaneceu até 1985. A chegada de Porchat a UNICAMP foi, definitivamente, meteórica. O projeto de criação do CLE foi, segundo seu relato, consequência da evoluçáo do seu pensamento filosófico e do seu caminho em direção ao ceticismo. Ele dizia que embora tivesse tido contato com o ceticismo deste 1967, ele só se tornou cético na UNICAMP (portanto após 1975). O CLE, disse ele na sua conferência proferida na Cerimônia de outorga do título de professor emérito, "é fruto tardio do ceticismo grego antigo" (Porchat, "Conferência na Cerimônia de outorga do título de professor emérito”). Nesta conferência ele chegou a sugerir, fazendo graça, que fosse erguida, junto à entrada do CLE, uma estátua do Sexto Empírico, que deveria ser seu patrono.

O contato de Porchat com o ceticismo, segundo ele, se deu em 1967. Em 1968 ele ministrou pela primeira vez, junto ao departamento de Filosofia da USP, um curso dedicado à obra de Sexto Empírico e ao ceticismo grego. Embora, até I975,

\footnotetext{
5 Atualmente, há 44 cursos de mestrado e 25 cursos de doutorado em Filosofia, reconhecidos pela CAPES, vide anpof.org.br
} 
ele ainda não fosse cético, durante estes anos ele lidou com muitos textos sobre ceticismo grego, textos estes lhe causaram "uma enorme perturbação filosófica". Disse Porchat, na mesma conferência acima referida: "Graças ao ceticismo, eu deixei de acreditar nos sistemas metafísicos e deixei de acreditar nas, assim chamadas, verdades de filósofos ou cientistas" (Ibid.).

Tal como ele concebia o ceticismo naquela ocasião, concepção esta que se altera posteriormente, tudo que a filosofia buscava de certeza e conhecimento e que Porchat não encontrava, ele pensa encontrar na lógica formal. Então ele começa a dedicar-se vorazmente ao estudo da lógica, da teoria dos conjuntos, álgebra, da metamatemática, epistemologia e história da matemática. O que ele o faz mais intensamente durante o seu estágio de dois anos pós-doutorado em Berkeley na Universidade da Califórnia.

Mas, era preciso mais: era necessário, segundo ele, criar espaços dedicados sobretudo ao estudo da lógica e epistemologia. Durante seu pós-doutorado ele começa a acalentar o projeto de criação de um centro de pesquisa dedicado "aos estudos de teoria do conhecimento, epistemologia, lógica e filosofia da ciência" (Porchat, apud Nobre, 2000, p. 124). O projeto que culminará com a criação do CLE é, portanto, anterior a ida dele para a UNICAMP.

Inicialmente, Porchat planejava criar tal centro na USP, onde era docente. Creio que, este projeto chegou a ser aprovado pelo Departamento de Filosofia da USP. Mas, naquela ocasião, a USP já era uma Universidade consolidada e com uma estrutura bastante estabelecida e, consequentemente, mais burocratizada, menos aberta a projetos pouco ortodoxos, como era o do Porchat, que incluía não apenas a criação de um centro de pesquisa interdisciplinar nas áreas de lógica, epistemologia e história da ciência, reunindo filósofos, linguistas e cientistas do Brasil e do exterior, mas também a criação de revistas de feitio internacional (uma revista de filosofia, outra de lógica e outra de história e filosofia da ciência) e a criação de um curso de pós-graduação em lógica e filosofia da ciência, provavelmente o primeiro na América Latina. Ele previa, também, a realização de seminários regulares (semanais) e congressos interdisciplinares com convidados do Brasil e do exterior. De fato, era um projeto gigante e meio megalomaníaco, como ele mesmo reconhecia. O próprio Porchat dizia que ao reler as primeiras versóes de seu projeto, ele se espantava com sua ousadia de propô-lo. E se perguntava: "Será que eu sofria de megalomania?"

A Unicamp, neste momento, era muito jovem: tinha apenas nove anos. Criada em 1966, a UNICAMP contava nestes primeiros anos apenas com alguns poucos institutos. O IFCH, o Instituto de Filosofia e Ciências Humanas, só foi criado em 1968. Aliás, quando o IFCH foi criado, sequer contemplava um Departamento de 
Filosofia, que figurava em seu nome, tinha apenas o Departamento de Ciências Sociais, o Departamento de Linguística (que em 1977 torna-se um instituto autônomo, o Instituto de Estudos da Linguagem - IEL) e Departamento de Economia e Planejamento Econômico (que em I984, se transformou no Instituto de Economia - IE). Era tudo muito novo. A Unicamp, naquele momento, tinha uma estrutura muito mais flexível que a USP. O Conselho Universitário da UNICAMP nem estava plenamente estruturado. E, especialmente, a UNICAMP tinha um reitor, e seu criador, que era um visionário: Professor Zeferino Vaz.

De fato, o Zeferino ao criar a UNICAMP visava uma universidade moderna e eficiente, o que fazia com que ela estivesse muito mais aberta a novos projetos. A concepção de Zeferino de Universidade era que, para uma Universidade funcionar ela precisa primeiro de cérebros, segundo de cérebros, terceiro de cérebros, depois bibliotecas, laboratórios, equipamentos e, por último, edifícios ${ }^{6}$. Aliás, Zeferino dizia vislumbrar um campus com "edifícios sóbrios, sem fachadas imponentes e sem os luxos de acabamento e de espaços construídos sem qualquer utilidade" 7 . De fato, ele construiu a UNICAMP num canavial, por onde se espalhavam alguns barracóes, bastante improvisados. E muito feios. Não havia qualquer preocupação estética. A grande preocupação dele era em reunir na UNICAMP as melhores 'cabeças'. E para isso ele não media esforços. Ele concentrava em suas mãos o poder de criar o que considerasse importante. Ele concentrava em suas mãos o poder de contratar e nomear os pesquisadores mais competentes que se dispusessem a embarcar neste novo projeto de Universidade.

De fato, ele era, como alguns o classificam, um "déspota esclarecido". A maneira como ele dirigia a UNICAMP hoje seria impensável. Mas, naquela ocasião foi decisiva. Rogério, amigo de Porchat de longa data (desde a época do colégio em 1948) começou a insistir que Porchat levasse para a UNICAMP o tal projeto de criaçáo de um centro de pesquisa interdisciplinar nas áreas de lógica, epistemologia e história da ciência. No feriado de 7 de setembro de 1975, Porchat liga para o Rogério dizendo que estava propenso a aceitar a sua sugestão. Imediatamente, Rogério marca uma reuniāo entre Porchat e o então reitor da Unicamp, Zeferino Vaz. Três dias depois deste

\footnotetext{
${ }^{6}$ Cf. Gomes, 2006, p. 58. Segundo Eustáquio Gomes, em seu livro 'O Mandarim: história da infância da UNICAMP', Zeferino considerava que: "Instituiçóes científicas, universitárias ou isoladas constroem-se com cérebros e não com edifícios. Escala de prioridade: a) cérebros b) cérebros; c) cérebros; d) bibliotecas; e) equipamentos; f) edifícios. Isto é importante acentuar porque neste país acreditamos em fachadas" (Gomes, 2006, p. I00). E estes cérebros deveriam trabalhar em tempo integral e dedicação exclusiva.

7 Gomes, 2006, p. 48. No relatório apresentado ao governador nos primeiros meses após a criação da UNICAMP, Zeferino, segundo Gomes, resumia seu plano: Os edifícios deveriam ter no máximo três andares, evitando-se uso de elevadores, "serão feitos de molde a disporem de amplas áreas com um mínimo de alvenaria fixa, divididas através de paredes removíveis, permitindo alteraçóes rápidas em função de necessidades futuras”.
} 
telefonema a tal reuniáo acontece. Porchat teve apenas alguns poucos dias para reunir as informaçóes para compor um pequeno projeto de duas páginas que ele submeteu ao Prof. Zeferino Vaz. A proposta contemplava a implantação de um Centro de estudos e pesquisas nas áreas de lógica, epistemologia e história da ciência bem como a criação de um programa de pós-graduação em Lógica e Filosofia da Ciência.

$\mathrm{Na}$ sua fala por ocasião do recebimento do título de professor emérito, Porchat disse que: "criar o Centro de Lógica, Epistemologia e História da Ciência foi a realização de um sonho". Ele gostava de se referir aos primeiros anos de criação e implementação do CLE, como os anos heroicos (de $1975 \mathrm{em}$ diante). Tal projeto, além de preencher uma grande lacuna, converteria a Unicamp, na década de setenta, num local privilegiado de encontro e diálogos entre filósofos, lógicos, historiadores, sociólogos, matemáticos, físicos, psicanalistas até então dispersos nos vários centros universitários do país. Zeferino entusiasmou-se com a ideia já nesta primeira reunião (ıo/o9/1975) e neste mesmo dia, após 35 minutos de conversa, se decidiu pela criação do CLE e pela nomeação de Porchat na UNICAMP.

Porchat levou um susto. Ele pensava que entre a apresentação de seu projeto inicial e decisão de criar o CLE levaria um tempo. Ele imaginava que teria que elaborar um projeto mais detalhado. E mais, que a efetiva criação do CLE levaria cerca de um ano e meio ou dois anos. Mas, o Zeferino queria efetivar a nomeaçáo de Porchat na semana seguinte. O que foi feito. Zeferino pede então que Porchat indique nomes para serem contratados. Porchat lista de cabeça uma dezena de jovens brilhantes filósofos, a maioria doutorandos e professores do departamento de Filosofia da USP, entre os quais Carlos Alberto Ribeiro de Moura, Luiz Henrique Lopes dos Santos, e Andréa Loparic. Porchat citou também dois professores argentinos que anos antes tinham enviado a ele seus curricula pleiteando uma vaga na USP: o lógico Carlos Alberto Lungarzo e historiador da filosofia Ezequiel de Olaso.

Mas, Porchat citou estes nomes todos sem nem mesmo consulta-los pois imaginou que era apenas para que o Zeferino tivesse ideia da dimensão do projeto. Mas, qual não foi sua surpresa quando Zeferino conclui: "entre em contato imediato com eles e na quarta-feira que vem, dia 17 [de setembro] traga os nomes dos que aceitaram e eu vou nomeá-los todos" (Porchat, conferência na Cerimônia de outorga do título de professor emérito). Outro susto. Como ele nunca havia conversado com estas pessoas sobre tal projeto, ele náo tinha ideia se eles concordariam em ir para a UNICAMP. Além disso, antes de uma possível nomeação, aqueles que eram docentes da USP teriam que se demitir daquela universidade. Sair de uma universidade estabelecida e ir para uma universidade recém fundada, que mal tinha prédios.

Em relação aos professores argentinos, Porchat ficou mais atônito, especialmente quando percebeu que Zeferino também planejava nomeá-los. Mas, provavelmente, 
estes dois argentinos, Carlos Lungarzo e Ezequiel de Olaso, sequer sabiam que a UNICAMP existia. (Porchat, apud Nobre 2000, p. I24). Porchat pensou, segundo me relatou certa vez: "eu sou maluco, como eu pude indica-los ao reitor: eu nem sei se estes caras estão vivos. Não os conheço apenas recebi seus currículos anos atrás, li seus textos e achei o trabalho de ambos brilhante". De fato, Porchat não sabia nada sobre eles: ainda que estivessem vivos, ele não sabia se eles ainda moravam na $\mathrm{Ar}$ gentina, ou tinham ido para alguma universidade europeia ou americana. E ainda que permanecessem na Argentina. Onde, encontra-los?

Ao que Zeferino disse: "então, você vai à Argentina e fala com eles, porque nós temos pressa". (Ibid.). Pressa de que? A resposta era simples. A UNICAMP tinha um orçamento que precisaria ser executado em 1975. Portanto, havia necessidade de empenhar esta verba o quanto antes. Até o final de setembro de 1975 todos já precisariam estar nomeados. Mas, e se alguém fosse nomeado e não quisesse? Questiona Porchat. Simples, responde Zeferino, neste caso a gente o demite, isto porque, de acordo com Zeferino, segundo relata Porchat nesta entrevista dada a Nobre, para Zeferino era muito mais fácil demitir do que nomear. "Para demitir, dizia ele, basta a minha vontade. Para nomear, preciso ter verbas, ter orçamento, respeitar datas. Então eu vou nomear todo mundo e, se eles não puderem vir, demito” (Ibid.).

Felizmente, todos os professores brasileiros sugeridos por Porchat toparam e uma semana depois uma dezena de filósofos já havia sido contratada para a implantação do Centro de Lógica, Epistemologia e História da Ciência e também do Curso de Pós-Graduaçáo em Lógica e Filosofia da Ciência. Porchat consegue contato telefônico com os dois professores argentinos e duas semanas depois, Porchat segue para a Argentina para conversar com Carlos Alberto Lungarzo e Ezequiel de Olaso. Eles pediram três dias para pensar. E finalmente, aceitaram vir para Campinas com família e tudo. Só quando chegaram a Campinas, eles descobriram que já estavam nomeados e já eram docentes da UNICAMP. Só então descobriram que já estavam na folha de pagamento.

De fato, são anos heroicos.

Quando Porchat retorna da Argentina, ele descobriu que todos tinham sido nomeados para o Instituto de Filosofia e Ciências Humanas-IFCH e não para o CLE. Isto ocorreu, pois, seu projeto incluía a criação de um curso de pós-graduação, mas na UNICAMP apenas unidades de ensino podem ministrar cursos de graduação e pós-graduação. Portanto, o curso de pós-graduação em Lógica e Filosofia da Ciência, assim como seus docentes, teria que ser alocado em algum instituto e Zeferino escolheu o Instituto de Filosofia e Ciências Humanas.

Sem dúvida isso causou um grande mal-estar junto ao $\mathrm{IFCH}$, que não havia sido consultado sobre a possibilidade da criação de um novo curso de pós-graduação nem 
sobre a contratação de cerca de dez ou doze professores de filosofia, alocados inicialmente junto ao departamento de Ciências Sociais. Um novo curso e seus docentes "caíram de paraquedas" no IFCH. Porchat rapidamente se encarrega de criar o departamento de Filosofia e todos migram para o novo departamento.

O Porchat levou para a UNICAMP, naquela ocasião, pessoas extraordinárias e de múltiplos interesses, mas que se distinguiam por um elevadíssimo grau de rigor. Já em 1975, foram para lá, alguns professores da USP: Carlos Alberto Ribeiro de Moura, que permaneceu na UNICAMP entre 1975 e 1984, Luiz Henrique Lopes dos Santos, que permaneceu de 1975 a 1982, Luiz Roberto Monzani, de 1975 a 2004 e Andréa Loparic, de 1975 a 1994. Neste mesmo ano foi contratado o gaúcho Nelson Boeira, que lá permaneceu até 1983). Em 1977, outro gaúcho, Balthazar Barbosa Filho, que permanece na UNICAMP até 1986. Ainda em I977, chegam também o Zeljko Loparic e Marcos Lutz Müller. Alguns anos depois chega João Carlos Brum Torres, que atuou como docente da UNICAMP de 198I a 1983. Nestes primeiros anos chegam também muitos estrangeiros: Gérard Lebrun, Michel Debrun, Harvey Brown, hoje professor na Universidade de Oxford e que permaneceu na UNICAMP de 1978 a 1984, Carlos Alberto Lungarzo, Andréas Raggio, Ezequiel De Olazo, entre outros. Era sem dúvida um timaço.

Em 1977, o Programa de Pós-graduação, idealizado pelo Porchat, é criado tendo como princípio norteador, desde a sua criação a ideia de dar a seus alunos uma sólida formação nas áreas canônicas da História da Filosofia aliada a linhas de pesquisa intere mesmo transdisciplinares, estimulando a produção de um pensamento original. Esse perfil acadêmico é o que permitiu desde o início tanto uma produção diversificada e de qualidade, como atrair bons candidatos das mais diversas áreas e interesses.

Embora seja inegável a importância do professor Oswaldo Porchat para a UNICAMP, para Centro de Lógica, Epistemologia e História da Ciência e para o Departamento de Filosofia, a meu ver merece especial destaque sua importância no que tange à criação deste que se tornou um dos mais respeitados programas de pósgraduação em Filosofia. O desenvolvimento deste programa de pós-graduação é uma história que eu tive o privilégio de conhecer de perto. Eu entrei, como aluna, na pós-graduação neste departamento em I98I, portanto, faço parte da quarta turma, e lá defendi o meu mestrado em 1987.

Assim que me formei em Física na USP, no campus de São Carlos, em 1980, resolvi ir para a UNICAMP fazer mestrado em Física Estatística. Numa conversa com o professor Bento Prado Jr, que eu conhecera em São Carlos por outras vias num grupo de estudos de filosofia política, sem grandes preleçôes e, certamente, já prevendo o impacto que teria sobre mim a sua indicação, o professor Bento sugeriu que eu procurasse um "certo" professor Oswaldo Porchat Pereira no Departamento 
de Filosofia da UNICAMP, onde iniciara recentemente (1977) um programa pósgraduação em Lógica e Filosofia da Ciência.

Foi com uma carta de apresentaçáo do professor Bento que cheguei ao Departamento de Filosofia e ao Centro de Lógica, Epistemologia e História da Ciência, em novembro de 1980 , e não saí mais. Esta conversa com o professor Porchat, que certamente ele nem devia se lembrar, visto que provavelmente teve inúmeras conversas semelhantes com outros alunos, marcou-me profundamente. Ver o professor Porchat discorrer com tamanho entusiasmo sobre o Programa de Pós-graduação que ele criara e especialmente com tamanha simplicidade, clareza, rigor e elegância sobre os mais diferentes temas ligados à Filosofia deixaram-me fascinada.

Eu vinha de outra área (da Física), não estava familiarizada com o jargão filosófico, mas ele conseguia algo surpreendente: se expressar com absoluto rigor, mas sem recorrer a "termos esdrúxulos nem a um jargão complicado". Aliás, esta forma de fazer filosofia foi algo que ele sempre buscou, isso ficou claro naquela entrevista dada a Marcos Nobre a que me referi acima. Disse ele:

Em filosofia é "realmente necessário não escrever em 'filosofês', mas conseguir ser claro usando os meios da língua vernácula e escrever de tal modo que um homem de relativa informação e, é claro, com uma certa base cultural possa compreender. Continuo, concluiu ele, desconfiado até hoje dos que falam difícil em filosofia. Exprimir-se de modo difícil [concluiu Porchat] é na verdade deixar transparecer uma certa falta de rigor intelectual" (Porchat, in Nobre 2000, p. 125).

Posso dizer, sem nenhuma dúvida, que ao sair desta conversa com o professor. Porchat eu já tinha tomado a minha decisão de abandonar o mestrado em Física, transferindo-me para o de Filosofia. Em 198I, prestei o "tão temido" exame de seleção para ingresso no Programa de Pós-graduação em Lógica e Filosofia da Ciência da UNICAMP e entrei. Sem receio de parecer piegas, eu posso dizer que ter sido aluna deste programa, nestes primeiros anos, foi uma experiência extraordinária sob todos os pontos de vistas e forjou, definitivamente, o meu futuro profissional. O bacharelado em Física tinha me dado disciplina de estudo, mas, certamente, eu jamais havia estudado tanto.

Havia no departamento de Filosofia uma preocupação muito grande em nos dar uma sólida formação filosófica, durante os três primeiros anos de pós-graduação, os alunos praticamente só faziam disciplinas, o que se justifica, visto que a maioria dos alunos do programa não tinha uma formação filosófica. Éramos alunos oriundos de diferentes graduaçóes, o que permitia, por um lado, uma rica interação interdisciplinar, mas que exigia por outro lado um enorme investimento na nossa formação. Tínhamos, no departamento, regularmente seminários interdisciplinares, dos quais 
participavam todos os professores e alunos da filosofia, alguns professores da física e da matemática. Além destes seminários, havia a organização regular de colóquios e congressos de caráter internacional. O que na época no Brasil era muito raro.

Nos meus seis anos de pós-graduaçáo ocorreram trinta e cinco colóquios e congressos (alguns nacionais e outros internacionais) reunindo e pondo em contato pessoas que trabalhavam em diferentes centros. Hoje é comum a realização de colóquios e congressos, mas naquela época isso era uma novidade. Muitos professores franceses, ingleses, alemães e americanos foram para a UNICAMP como professores visitantes e ministravam alguma disciplina no programa ou participavam de algum evento. Lembro-me de Gilles-Gaston Granger, Donald Davidson, Maurice Clavelin, François De Gand, Harvey Brown, Eduardo Rabossi, John Searle entre outros. Nos primeiros sete anos, mais de setenta filósofos estrangeiros foram para a UNICAMP. Também inúmeros brasileiros, que embora não fizessem parte do programa, participavam regularmente da vida do departamento de Filosofia e do CLE, entre os quais eu destacaria Raul Landin, Guido de Almeida, Bento Prado Jr e inúmeros outros. Eu poderia continuar listando um sem número de pesquisadores que foram a UNICAMP a convite de Porchat.

De fato, era um programa de pós-graduação excepcional. E por incrível que pareça, nós alunos tínhamos consciência do que era esse programa e o que era participar deste projeto, e isso nos dava uma responsabilidade imensa. Nós estudávamos muito, acho que não fazíamos outra coisa. E eu vinha de uma experiência de muito estudo e disciplina, cursara graduação em física na USP.

A marca que Porchat imprimiu neste programa, neste período, e que o caracterizava era a atmosfera de debate e de discussão que se instalou ali. Atmosfera esta fundamental para uma sólida pesquisa em filosofia. A possibilidade de expor e debater os resultados parciais de nossas pesquisas contribuiu de maneira decisiva para o amadurecimento intelectual não só dos alunos, mas também de todos os pesquisadores que por ali passavam. Existia um ambiente de pesquisa e discussão contagiante, mas havia, principalmente, um enorme entusiasmo do corpo docente e discente. Balthazar Barbosa Filho ao se referir a sua participação na história deste programa, também destacou a atmosfera de debate que ali se instalou. Na sua entrevista dada a Nobre, e publicada no livro Conversas com Filósofos Brasileiros, citado acima, Balthazar afirmou:

Antes, qualquer discussão de ideias filosóficas, qualquer discordância ou crítica veemente a uma tese, exposição ou argumento, era tomada como uma agressão pessoal, e imediatamente a pessoa criticada se punha em legítima defesa. Isso fazia com que a discussão degenerasse rapidamente. A UNI- 
CAMP, naquela ocasião, conseguiu criar — o que felizmente depois se espalhou - a tradição da discussão feroz, acesa, mas que, no entanto, permanecia exclusivamente no terreno das teses e das ideias, e não no terreno pessoal. Isso foi a contribuiçấo [concluiu ele] mais importante da UNICAMP” (Barbosa, in Porchat, in Nobre, 2000, p. 406).

E eu ousaria dizer que isso foi, por sua vez, a contribuição mais importante de Porchat para a UNICAMP, pois ele foi de fundamental importância na criação deste ambiente, na criação desta "tradição da discussão feroz, acesa, mas que, no entanto, permanecia exclusivamente no terreno das teses e das ideias, e não no terreno pessoal”. Embora, ele tivesse posiçóes filosóficas absolutamente precisas, um filósofo neopirrônico, institucionalmente ele sempre adotou uma postura generosa de diálogo com pesquisadores de diferentes matizes.

Para encerrar eu gostaria de parafrasear o título de uma conferência ministrada por Porchat num dos primeiros colóquios que eu organizei como parte das atividades do V Encontro Nacional de Filosofia da ANPOF, ocorrido em Diamantina, em outubro de 1992. Ele a intitulou "eu era feliz e não sabia". Eu gostaria de dizer que eu, e estou certa que todos os meus colegas do programa de pós em Lógica e Filosofia da Ciência concordariam: nós éramos felizes, e sabíamos.

\section{Bibliografia}

Gomes, E. (2006). O Mandarim: história da infância da UNICAMP. Editora da Unicamp: Campinas.

Marcolin, N. (2016). "A concepção de uma Universidade”, Revista FAPESP: http://revistapesquisa.fapesp.br/2016/1o/o3/a-concepcao-de-uma-universidade/

Nobre, M. \& Rego, J. (2000). Conversas com Filósofos Brasileiros. Ed. 34: São Paulo.

Porchat Pereira, O. (2OII) "Conferência proferida em 23 de novembro de 201 r na cerimônia de outorga do título de professor emérito ao Professor Oswaldo Porchat Pereira", in: https://www.unicamp.br/unicamp/ju/radio/video/tv-unicamp-resgata-discurso-de-oswaldo-porchat

http://www.unicamp.br/unicamp/noticias/20II/unicamp-concede-ot\% 3 \% ADtulo-de-professor-em $\% \mathrm{C}_{3} \% \mathrm{~A}_{2}$ rito-ao-fil\% $\mathrm{C}_{3} \% \mathrm{~B} 3$ sofo-oswaldo-porchat 